\title{
An Efficient and Color-Tunable Solution-Processed Organic Thin-Film Laser with a Polymeric Top-Layer Resonator
}

\author{
José A. Quintana, José M. Villalvilla, Marta Morales-Vidal, Pedro G. Boj, Xiaozhang Zhu, \\ Nopporn Ruangsupapichat, Hayato Tsuji, Eiichi Nakamura, and María A. Díaz-García*
}

Thin film organic lasers represent attractive light sources for numerous applications. Currently, efforts are devoted to the development of low-cost high-performance and color-tunable devices, whereby both the resonator and the active layer should consist of solution-processable organic materials. Herein, solution-processed distributed-feedback lasers are reported with polymeric resonators on top of active films of perylene orange or carbon-bridged oligo( $p$-phenylenevinylene) dispersed in polystyrene, which combine these properties. These lasers emit in the 520-595 $\mathrm{nm}$ range and show low thresholds $\left(\approx 1 \mathrm{~kW} \mathrm{~cm}{ }^{-2}\right)$ and long operational lifetimes $\left(7 \times 10^{5}\right.$ pump pulses), which are comparable to other state-of-the-art lasers that contain the same active materials but resonators made on inorganic substrates. Due to this top-layer resonator configuration, the laser slope efficiencies of the present devices are remarkably superior. A centimeter-size device emitting at different wavelengths within a broad spectral range, based on a perylene-based film of uniform thickness that contributes to preserve a low threshold, is demonstrated.

\section{Introduction}

Thin film organic lasers (TFOLs) have recently received great attention. ${ }^{[1-4]}$ Among them, distributed-feedback (DFB) lasers, which contain a waveguide active film (AF) and a relief grating

Dr. J. A. Quintana, Dr. P. G. Boj

Dpto. Óptica

Instituto Universitario de Materiales de Alicante

(IUMA) and Unidad Asociada UA-CSIC

Universidad de Alicante

Alicante 03080, Spain

Dr. J. M. Villalvilla, Dr. M. Morales-Vidal, ${ }^{[+]}$Prof. M. A. Díaz-García Dpto. Física Aplicada and IUMA

Universidad de Alicante

Alicante 03080, Spain

E-mail: maria.diaz@ua.es

Dr. X. Zhu, Dr. N. Ruangsupapichat, Prof. H. Tsuji, ${ }^{[++]}$Prof. E. Nakamura

Department of Chemistry

School of Science

The University of Tokyo

Hongo, Bunkyo-ku, Tokyo 113-0033, Japan

[+]Present address: Dpto. Física Aplicada, Grupo de Investigación en Aplicaciones del Láser y Fotónica, Universidad de Salamanca, Salamanca E-37008, Spain

${ }^{[++}$Present address: Department of Chemistry, Faculty of Science,

Kanagawa University, 2946 Tsuchiya, Hiratsuka 259-1293, Japan

DOI: 10.1002/adom.201700238 as a laser resonator, have found a variety of applications in spectroscopy, ${ }^{[5]}$ optical communications, ${ }^{[6]}$ and sensing. ${ }^{[7-10]}$ DFB lasers can provide narrow single mode emission (linewidth $<1 \mathrm{~nm}$ ) and require only low pump energy for their operation, i.e., they show a low threshold. The resonator is easily integrated into other devices, and it can be implemented with field-effect-transistor geometry, which promises potential for the development of electrically pumped TFOLs. Moreover, DFB lasers can be mechanically flexible, and their production costs are relatively low. DFB gratings are usually fabricated by electron beam lithography, nanoimprint lithography (NIL), or holographic lithography (HL). ${ }^{[11]}$ A particular advantage of the latter is its capability to produce small structures of different dimensionality over a large area (up to a few $\mathrm{cm}^{2}$ ) in a simple and low-cost manner, which can be exploited to fabricate wavelength-tunable devices on a single chip.

So far, different DFB architectures, with gratings fabricated by various methods, have been reported, ${ }^{[1-4]}$ whereby efforts have been devoted predominantly to lowering the threshold. The lowest values $\left(<1 \mathrm{~kW} \mathrm{~cm}^{-2}\right)$ have been achieved with lasers whose DFB gratings are engraved on conventional inorganic substrates (e.g., glass or $\mathrm{SiO}_{2}$ ), onto which the active films are deposited (this configuration will henceforth be denoted as standard; Std). Other studies, aimed at improving device integration, reducing device costs, and achieving mechanical flexibility, have focused either on architectures with gratings imprinted directly on the active film, ${ }^{[12-17]}$ or on systems wherein both the active material and the resonator, which is generally located below the active film ${ }^{[18-22]}$ and only in few cases on top of it, ${ }^{[23,24]}$ were processed from solution. Unfortunately, the thresholds of these solution-processed lasers are generally high $\left(>8 \mathrm{~kW} \mathrm{~cm}^{-2}\right)$, except for few exceptions. ${ }^{[19]}$ Finally, several strategies have been proposed in order to accomplish wavelength tunability in a single device. ${ }^{[1-4]}$ For example, by using multiple gratings (e.g. segmented substrates with a stepped grating period), ${ }^{[25]}$ a wedged-shape active film (i.e. with a continuously variable thickness), ${ }^{[26]}$ mechanical stretching, ${ }^{[27]}$ photoisomerizable azo-polymers, ${ }^{[28]}$ or photochromic molecules doped into the active film. ${ }^{[29]}$ Some works have demonstrated electrical-tuning by combining an elastic DFB laser with an electroactive substrate, ${ }^{[30]}$ or by including a layer contaning a 
nonlinear optical molecule. ${ }^{[31]}$ Unfortunately, the implementation of most of these tunable devices is often either very expensive and/or sophisticated, or might penalize other laser parameters. For example, the use of the wedged-shape configuration, ${ }^{[26]}$ imposes a limitation on the threshold, which is highly dependent on film thickness, and consequently also on the operational durability.

We have recently demonstrated that perylenediimide (PDI) and carbon-bridged oligo( $p$-phenylenevinylene) (COPV) dyes, dispersed in thermoplastic polymers such as polystyrene (PS) or poly(methylmethacrylate), represent some of the most successful dyes used in organic DFB lasers with gratings engraved on inorganic substrates. ${ }^{[32-37]}$ Such lasers exhibit very low thresholds (e.g., perylene orange (PDI-O): ${ }^{[33]} \approx 2 \mathrm{~kW} \mathrm{~cm}{ }^{-2}$; COPVs: ${ }^{[35]} 0.7 \mathrm{~kW} \mathrm{~cm}^{-2}$ ), very long lifetimes $\left(>10^{5}\right.$ pump pulses), ${ }^{[32,35]}$ and emission wavelengths that cover a wide range of the visible spectrum (COPVs: ${ }^{[35,37]} 380-600 \mathrm{~nm}$; PDIs: ${ }^{[34,38]}$ 555-630 nm), whereby the specific performance parameters depend on the selected COPV or PDI derivative and device parameters, such as film thickness and grating period. With those dyes in hand, subsequent efforts have been directed at resolving the challenge to develop an inexpensive DFB resonator that combines good laser performance characteristics with the ability to tune the laser wavelength using a single dye in a single device.

Herein, we report solution-processed organic DFB lasers with polymeric resonators on top of dye-doped polymer films (device type henceforth denoted as $\mathrm{R}_{\mathrm{T}}$ to account for "resistbased top-layer resonator") that exhibit all these desired properties. The active layer was first made using either PDI-O or COPV derivatives (COPV $n ; n=3,4$, and 6) dispersed in PS matrix using a hydrophobic solvent, followed by the deposition of a photoresist layer on top of it using water-soluble dichromated gelatine (DCG). Then, 1D relief gratings were engraved by HL over the DCG layer that serves as the resonator. The present process allowed us to obtain an active layer with uniform thickness across the whole device, which is a consequence of the use of materials for the active film and the resonator immiscible to each other and implies a more efficient use of the gain volume. Another important feature is that the relief grating, once the DCG film has been holographically exposed, is generated by a dry development process, which is different from the wet processing methods used in conventional classic holography to obtain volume refractive index patterns. These fabrication aspects are important for the successful operation of the device. This has previously been established on lasers with a top-resonator configuration, whose thresholds were relatively large (several tenths to hundreds of $\mathrm{kW} \mathrm{cm}^{-2}$ ) on account of fabrication difficulties. ${ }^{[23,24]}$

The $\mathrm{R}_{\mathrm{T}}$ type lasers prepared in this study emit in the 520-595 $\mathrm{nm}$ range and show excellent performance in terms of linewidth $(<0.13 \mathrm{~nm})$, threshold $\left(\approx 1 \mathrm{~kW} \mathrm{~cm}{ }^{-2}\right)$, and operational lifetime $\left(7 \times 10^{5}\right.$ pump pulses $)$. These parameters are comparable to those of Std-type lasers, which is a very remarkable fact, given that in the present case the resonator consists of an organic material. Moreover, the laser slope efficiency (LSE) is improved by a factor of $\approx 3$ when the $R_{T}$ instead of the Std configuration is used, which should be attributed to the location of the resonator on top of the active film instead of below.
Importantly, the performance of the $\mathrm{R}_{\mathrm{T}}$-type devices demonstrated herein has improved significantly (LSE and threshold values are increased 20 -fold and decreased sevenfold, respectively) in comparison to lasers with organic resonators, usually consisting of a resist layer with an engraved grating on its surface, located below the active film (device type henceforth denoted as $R_{B}$ to account for "resist-based bottom-layer resonator"). Finally, the use of a top-layer resonator configuration, combined with a large device size ( $\mathrm{cm}$ scale), facilitates the fabrication of various gratings with different period in a given device, which allows tuning the laser wavelength in a broad range $(\approx 50 \mathrm{~nm})$, while low threshold levels $\left(<5 \mathrm{~kW} \mathrm{~cm}{ }^{-2}\right)$ are preserved on account of the constant thickness of the active film across the device.

\section{Results and Discussion}

\subsection{Device Design}

The proposed $\mathrm{R}_{\mathrm{T}}$-type $\mathrm{DFB}$ scheme contains the following elements (Figure 1): an AF of uniform thickness $(h)$, deposited on top of a flat transparent fused silica (FS) substrate (size: $2.5 \times 2.5 \mathrm{~cm}^{2}$; thickness: $1 \mathrm{~mm}$ ), and a top-layer resonator consisting of a spin-coated DCG photosensitive resist (R) film, with one or several 1D gratings (period: $\Lambda$; depth: $d$; thickness of residual layer: $t$ ) engraved by HL after deposition. For comparative purposes, lasers with two other resonator configurations were prepared (Figure 1, Std and $R_{B}$ ), both with the active film on top of the DFB grating: the first (Std) contains a grating (size: $2 \times 2 \mathrm{~mm}^{2}$ ) on the center of a FS substrate engraved by thermal-NIL and ion beam etching; in the second one $\left(R_{B}\right)$, the grating was engraved by HL over a DCG layer deposited on FS.

It should be noted that the resist-based devices prepared $\left(R_{T}\right.$ and $\left.R_{B}\right)$ show several practical advantages with respect to the Std device: (i) the device fabrication is simpler, as ionbeam etching is not required; (ii) the resonator itself consists of a solution-processable organic material; and (iii) the grating size can be custom-tailored $\left(\mathrm{mm}^{2}-\mathrm{cm}^{2}\right)$, thus the method is less expensive compared to other lithographic methods.

The active films of all prepared DFB lasers consisted of spin-coated PS films (passive matrix) containing 1 or $2 \mathrm{wt} \%$ of a laser dye such as PDI-O, COPV3, COPV4, or COPV6 (see chemical structures in Figure 2).

Figure 3 shows an atomic force microscopy (AFM) image of one of the $\mathrm{R}_{\mathrm{T}}$-type fabricated gratings, particularly the one with $\Lambda=373 \mathrm{~nm}, d=90 \mathrm{~nm}$, and $t=0$, which shows a clear and well-defined structure. The grainy texture of the DCG layer is because of randomly distributed fibers (diameter: $\approx 50 \mathrm{~nm})^{[39]}$ formed during the grating fabrication process. These fibers determine the resolution limit of the photoresist material and thus, on the minimum $\Lambda$ value that can be fabricated, while preserving sufficient grating quality and contrast. For DCG and other similar photoresists, this minimum $\Lambda$ value is $\approx 250 \mathrm{~nm} \cdot{ }^{[20]}$

All DFB devices prepared in this work are 1D and operate in the second order of diffraction. In a 1D DFB laser, the wavelength that satisfies the Bragg condition $\left(\lambda_{\text {Bragg }}\right)$ is given by ${ }^{[1-4]}$ 


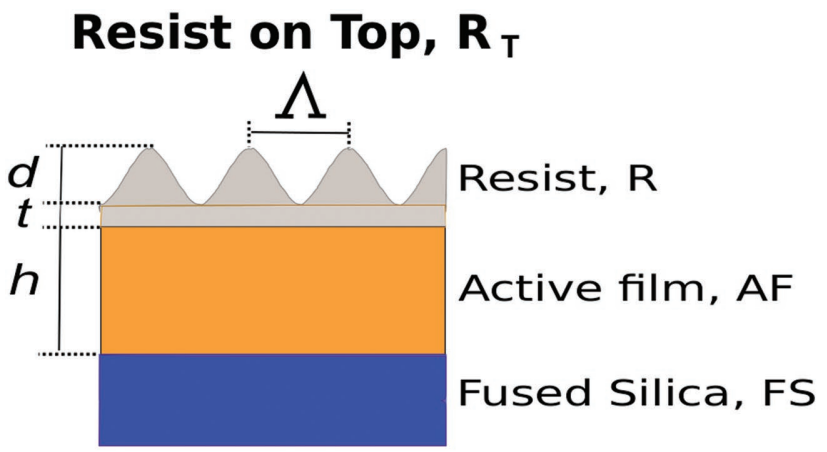

\section{Standard, Std}
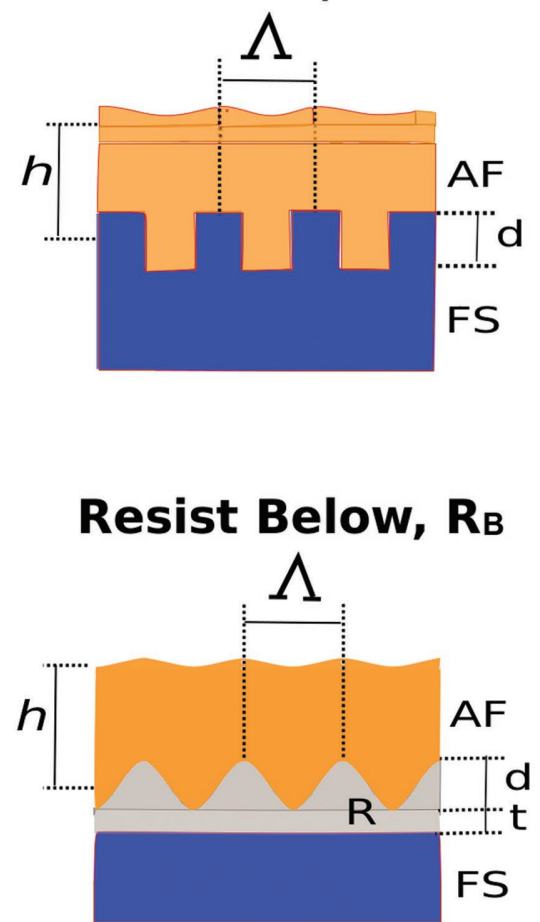

Figure 1. Device architectures used to fabricate DFB lasers (from top to down): Resist (R) resonator on top of the active film (AF), $R_{T}$-type; Resonator engraved on inorganic substrate (e.g., fused silica, FS) below the active film, standard, Std-type; Resist resonator below the active film, $R_{B}$-type; In all cases the resonator is a 1D relief grating with period $\Lambda$ and depth $d$; $t$ : thickness of the residual layer; $h$ : active film thickness.

$m \lambda_{\text {Bragg }}=2 n_{\text {eff }} \Lambda$

where $m$ is the order of diffraction, $n_{\text {eff }}$ is the effective refractive index of the waveguide, and $\Lambda$ is the grating period. Light with the resonant wavelength in the cavity, $\lambda_{\mathrm{Bragg}}$, is reinforced while it propagates along the waveguide, before it is diffracted in the grating in different directions. Second-order DFBs $(m=2$ in Equation (1)) are very attractive for certain applications such as sensing because light is coupled out of the film mainly in a direction perpendicular to the waveguide film by first-order diffraction. Moreover, such DFB lasers usually exhibit a singlemode emission spectrum, which consists of a single peak. It should be noted that when the coupled wave theory ${ }^{[40]}$ is applied to DFB lasers dominated by index coupling, emission should be expected to occur on a pair of wavelengths on either edge of a prohibited band centered at $\lambda_{\text {Bragg. }}$. However, in the case of second-order devices, the peak with the lower wavelength has a larger threshold due to radiation losses. ${ }^{[41]}$ Accordingly, a single-mode emission with the peak of the longer wavelength is observed, whereby defects or phase shifts in the nanostructure, which are typically used in first-order or 2D devices to obtain single mode emission, ${ }^{[42]}$ are not necessary.

Device design, i.e., selection of appropriate geometric parameters, to emit at a given wavelength, was done by calculating $n_{\text {eff }}$ for the fundamental transverse electric $\left(\mathrm{TE}_{0}\right)$ waveguide mode traveling in the active film for each of the device types, and the corresponding $\lambda_{\text {Bragg }}$ value via Equation (1).

\subsection{Linewidth, Threshold, and Operational Durability of the DFB Lasers}

The laser spectra of a set of $\mathrm{R}_{\mathrm{T}}$-type devices, which expand across different spectral regions that depend on the selection of the laser dye (PDI-O, COPV3, COPV4, or COPV6), are shown in Figure 4a. The corresponding devices are labeled $\mathrm{O}\left(\mathrm{R}_{\mathrm{T}}\right), 3\left(\mathrm{R}_{\mathrm{T}}\right), 4\left(\mathrm{R}_{\mathrm{T}}\right)$, and $6\left(\mathrm{R}_{\mathrm{T}}\right)$, and their geometric parameters are listed in Table 1. In all cases, single-mode emission was observed with linewidths (Figure 4b), defined by the full width at half maximum (FWHM), $<0.13 \mathrm{~nm}$, being this value limited by the spectrometer resolution.

A highly remarkable feature of the $\mathrm{R}_{\mathrm{T}}$-type $\mathrm{DFB}$ lasers prepared in this study is their very low thresholds $\left[\mathrm{O}\left(\mathrm{R}_{\mathrm{T}}\right)\right.$ : $\approx 2 \mathrm{~kW} \mathrm{~cm}^{-2}, 20 \mu \mathrm{J} \mathrm{cm}^{-2}$ pulse, $0.2 \mu \mathrm{J}$ pulse $^{-1} ; 6\left(\mathrm{R}_{\mathrm{T}}\right): \approx 1 \mathrm{~kW} \mathrm{~cm}^{-2}$, $10 \mu \mathrm{J} \mathrm{cm}^{-2}$ pulse, $0.1 \mu \mathrm{J}$ pulse ${ }^{-1}$ ] (Figure $4 \mathrm{c}$ and Table 1 ). These values are comparable to previously reported values for lasers based on the same active materials, but with a Std-type architecture. ${ }^{[3,35,43]}$ Considering the typically lower thresholds obtained with Std-type resonators, due to the generally higher grating quality and the better optical and mechanical properties of inorganic substrates, this result is highly remarkable. Moreover, in comparison to $\mathrm{R}_{\mathrm{B}}$-type devices based on DCG resonator materials, ${ }^{[20,44]}$ the thresholds of the $\mathrm{R}_{\mathrm{T}}$-type devices are one order of magnitude lower, which should be attributed to the location of the resonator on top of the active film. In order to provide additional insight for the rationalization of the high performance of the $\mathrm{R}_{\mathrm{T}}$-type lasers, an exhaustive comparison of the other architectures is included here for devices based on PDI-O. For this purpose, we built Std- and $\mathrm{R}_{\mathrm{B}}$-type PDI-O devices $\mathrm{O}(\mathrm{Std})$ and $\mathrm{O}\left(\mathrm{R}_{\mathrm{B}}\right)$ (Table 1 ), with similar geometric parameters and consequently similar emission wavelengths $\left(\lambda_{\mathrm{DFB}}\right)$. It should be noted that the superscripts (II or III) were assigned to the $\mathrm{R}_{\mathrm{B}}$-type and $\mathrm{R}_{\mathrm{T}}$-type devices in order to facilitate comparison and the same superscript was used for devices with similar geometric parameters. As shown in Table 1, the lasers that are compared, i.e., $\mathrm{O}\left(\mathrm{R}_{\mathrm{T}}\right)$ and $\mathrm{O}\left(\mathrm{R}_{\mathrm{T}}{ }^{\mathrm{II}}\right)$ to $\mathrm{O}(\mathrm{Std})$, as well as $\mathrm{O}\left(\mathrm{R}_{T}{ }^{\mathrm{II}}\right)$ to $\mathrm{O}\left(\mathrm{R}_{\mathrm{B}}{ }^{\mathrm{II}}\right)$, were built with similar parameters and they show similar emission wavelengths. These lasers were designed in order to emit as close as possible to the wavelength at which amplified spontaneous emission (ASE) occurs $\left(\lambda_{\mathrm{ASE}}\right)$, where the gain is maximal. The $\lambda_{\mathrm{DFB}}$ value can be controlled by a careful selection of the grating period $(\Lambda)$ and the film thickness $(h)$. The separation 

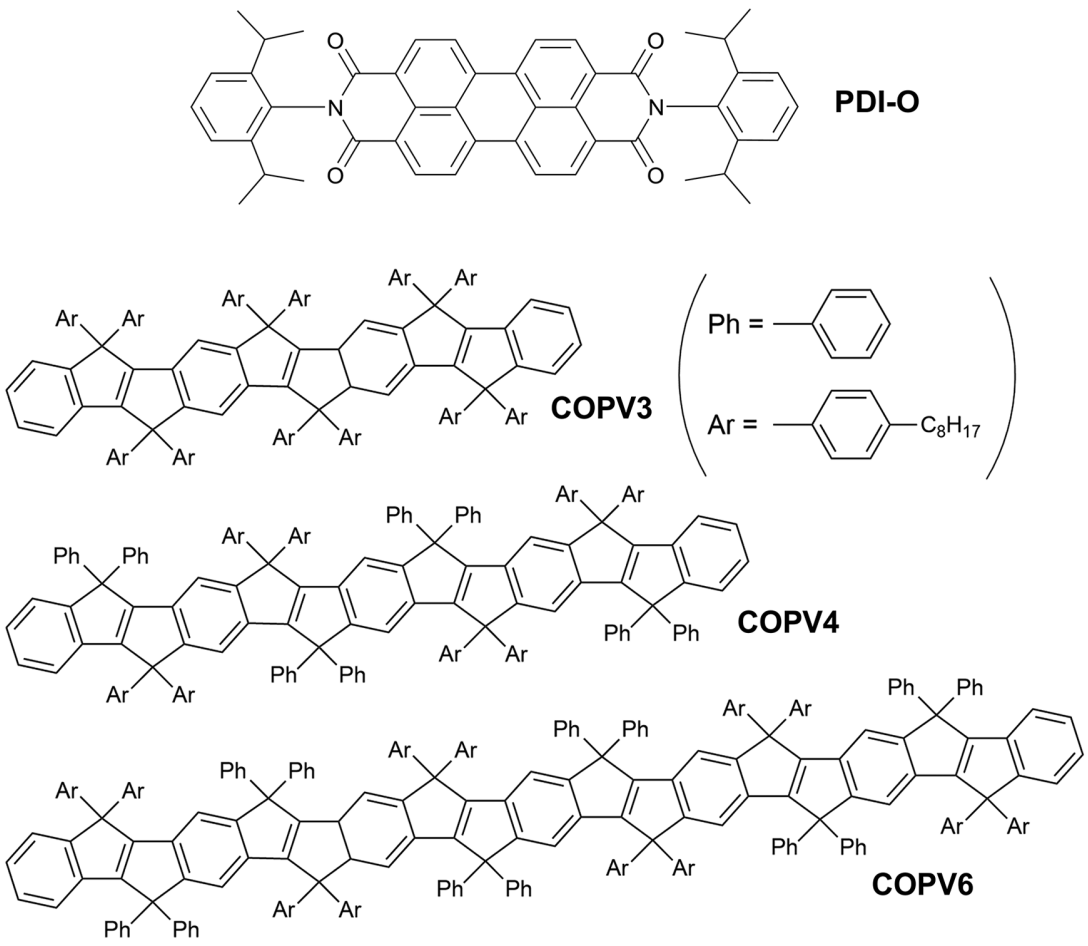

Figure 2. Chemical structures of laser dyes used to fabricate DFB lasers: perylene orange, PDI-O, and carbon-bridged oligo ( $p$-phenylenevinylene) derivatives, COPVn, with $n=3,4$, and 6 .

between $\lambda_{\mathrm{DFB}}$ and $\lambda_{\mathrm{ASE}}$ thereby exerts the dominant influence on the threshold. ${ }^{[38]}$ Another important aspect to optimize the threshold is to ensure a good confinement of the waveguide mode traveling on the active film, which requires $h$ values well above the cut-off thickness for the propagation on one mode. ${ }^{45]}$ For active films based on PS, $h$ should be $\approx 600 \mathrm{~nm}$, which is the value chosen for the four devices used in the comparison (Table 1). Subsequently, a grating period $(\Lambda=373 \mathrm{~nm})$ was chosen to obtain a $\lambda_{\mathrm{DFB}}$ close to that of $\lambda_{\mathrm{ASE}}(579 \mathrm{~nm})$. The thus obtained data (Table 1) confirm similar thresholds for $\mathrm{O}\left(\mathrm{R}_{\mathrm{T}}\right)$ $\left(2.5 \mathrm{~kW} \mathrm{~cm}^{-2}\right)$ and $\mathrm{O}(\mathrm{Std})\left(2.3 \mathrm{~kW} \mathrm{~cm}^{-2}\right)$. They also indicate that the $\mathrm{R}_{\mathrm{T}}$-type configuration $\left[\mathrm{O}\left(\mathrm{R}_{\mathrm{T}}{ }^{\mathrm{II}}\right): 2.7 \mathrm{~kW} \mathrm{~cm}^{-2}\right.$ ] leads to a threshold value several times lower than that of the $R_{B}$ configuration $\left[\mathrm{O}\left(\mathrm{R}_{\mathrm{B}}{ }^{\mathrm{II}}\right): 18 \mathrm{~kW} \mathrm{~cm}{ }^{-2}\right]$. The better performance of the $\mathrm{R}_{\mathrm{T}}$-type architecture with respect to the Std one was suggested

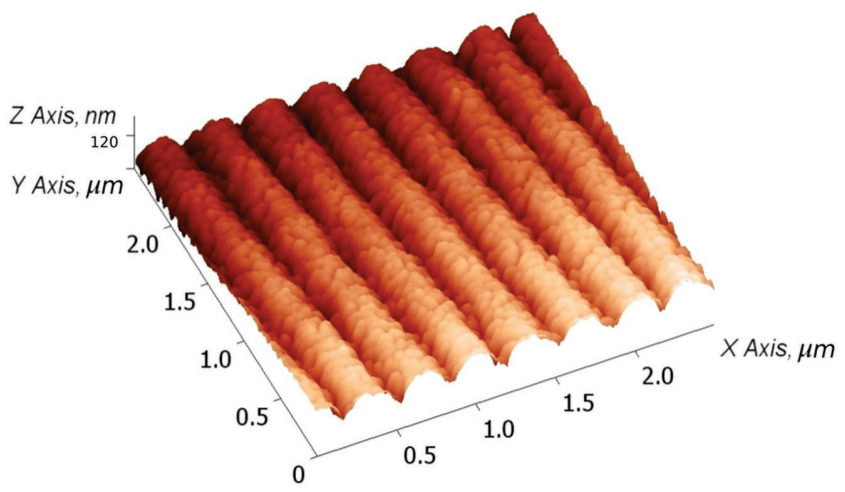

Figure 3. Atomic force microscopy (AFM) image of an $\mathrm{R}_{\mathrm{T}}$-type resonator with $\Lambda=373 \mathrm{~nm}, d=90 \mathrm{~nm}$, and $t=0$. by Zhai et al., ${ }^{[23]}$ from simulations based on the finite element method, although they were not able to confirm it experimentally because their gratings did not have sufficient quality. In Std-type devices, the optical field is partially distributed in the grating structure and in the active film, while in the $\mathrm{R}_{\mathrm{T}}$-type ones it is confined almost completely in the active guiding layer. This implies a much more efficent use of the active volume and better oscillation modes. In addition, the Std-type configuration is more sensitive than the $\mathrm{R}_{\mathrm{T}}$-type one to defects or additional modulation in the grating. If the $\mathrm{R}_{\mathrm{B}}$-type configuration is considered, instead of the Std one, the differences in performance when comparing to the $\mathrm{R}_{\mathrm{T}}$-type would be more drastic because the refractive index difference between the grating and the active film would be smaller. Therefore, a lower threshold would be expected for the $R_{T}$ architecture, with respect to that of Std and $R_{B}$, with a larger different in the latter case. In fact in previous studies, ${ }^{[20-44]} \mathrm{R}_{\mathrm{B}}$-type lasers showed larger thresholds (typically by one order of magnitude or more) than Std-type ones, as a result of the low refractive index contrast between the active film and the resonator layer.

The negative influence of poor confinement of the waveguide mode on the threshold is illustrated by the results obtained for $\mathrm{O}\left(\mathrm{R}_{\mathrm{T}}{ }^{\mathrm{III}}\right)$ and $\mathrm{O}\left(\mathrm{R}_{\mathrm{B}}{ }^{\mathrm{III}}\right)$ lasers, whose active films are thinner ( $h \approx 300 \mathrm{~nm}$ ), but still emit close to $\lambda_{\mathrm{ASE}}$. The decrease in $h$ leads to an approximately threefold increase of the threshold for $R_{T}$-type devices [cf. $O\left(R_{T}{ }^{I I I}\right)$ and $O\left(R_{T}\right)$ ], and a sevenfold increase for $\mathrm{R}_{\mathrm{B}}$-type devices [cf. $\mathrm{O}\left(\mathrm{R}_{\mathrm{B}}{ }^{\mathrm{II}}\right)$ and $\mathrm{O}\left(\mathrm{R}_{\mathrm{B}}{ }^{\mathrm{III}}\right)$ ] (Table 1 ). The major influence of decreasing $h$ on the latter type of lasers was attributed to the adverse effect of the modulation of the thickness of the active layer.

The operational durability of the prepared $R_{T}$-type $D F B$ lasers was also explored. They showed performances that are only slightly inferior to those of Std-type devices based on the same materials. Under ambient conditions and in the absence of encapsulation, Std-type DFB lasers based on PDI-O/PS or COPV/PS represent some of the most photostable devices reported in the context of organic DFB lasers. Under excitation using a pump intensity two times above the threshold, DFB half-life values, $\tau_{1 / 2}{ }^{\mathrm{DFB}}$, which are defined as the time (or the number of pump pulses) at which the DFB emission has decayed to half of its initial value, of $8 \times 10^{5}$ (PDI-O/PS) ${ }^{[33,43]}$ and $1 \times 10^{6}$ pump pulses (COPV6/PS) $)^{[35]}$ have been reported. Under identical pumping conditions, $\mathrm{O}\left(\mathrm{R}_{\mathrm{T}}\right)$ and $6\left(\mathrm{R}_{\mathrm{T}}\right)$ afforded $\tau_{1 / 2}{ }^{\mathrm{DFB}}$ values of $5 \times 10^{5}$ (PDI-O) and $7 \times 10^{5}$ pump pulses (COPV6), i.e., values that are diminished by a factor of merely 1.5 relative to those of the corresponding Std-type lasers. The origin of this slight decrease is not known at the moment. It might be due to the different device architecture; or maybe because the deposition of the photoresist layer over the active film affects its optical properties. Further experiments to clarify this are currently being performed, although in any case the 

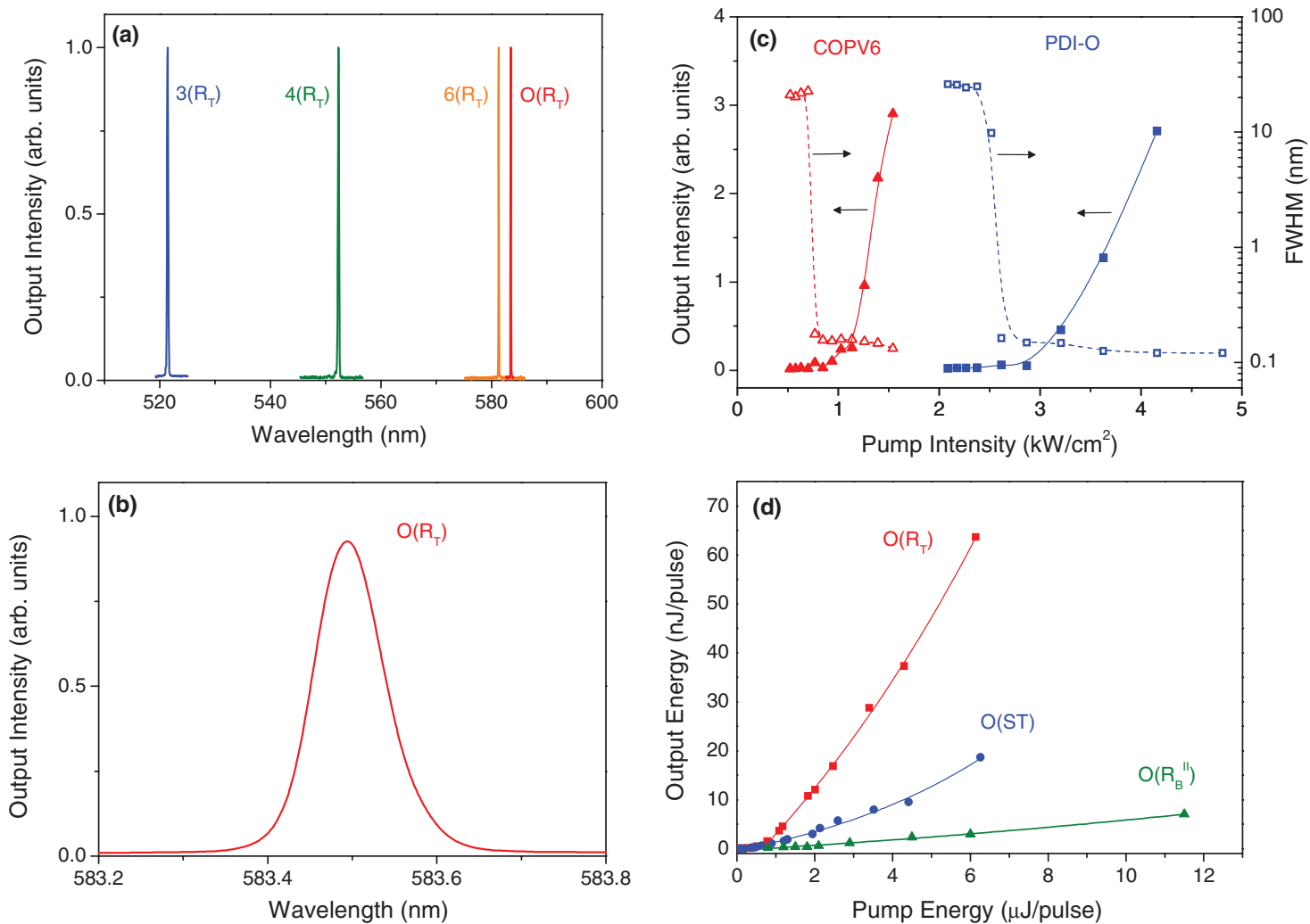

Figure 4. Laser properties of organic distributed feedback (DFB) lasers with resist resonator on top of the active film ( $R_{T}$-type). a) Spectra of $R_{T}$-type $D F B$ lasers based on active films of PDI-O or COPVn (with $n=3,4,6$ ) dispersed in polystyrene, labeled, respectively, as $O\left(R_{T}\right), 3\left(R_{T}\right), 4\left(R_{T}\right)$ and $6\left(R_{T}\right)$. b) DFB spectrum for device $\mathrm{O}\left(\mathrm{R}_{\mathrm{T}}\right)$ on an expanded scale. c) Linewidth, defined as the full width at half of the maximum (FWHM), and output intensity, both versus the incident pump intensity, for devices $O\left(R_{T}\right)$ and $6\left(R_{T}\right)$, for DFB threshold determination. d) Total output energy versus incident pump energy, for laser slope efficiency (LSE) determination, for device $\mathrm{O}\left(\mathrm{R}_{T}\right)$. Similar results (not shown in the figure) were obtained for device $\mathrm{O}\left(\mathrm{R}_{T}{ }^{\prime \prime}\right)$. Data for other PDI-O devices with different resonator types are included for comparison purposes $\left(O\left(R_{B}\right)^{11}\right.$ and $O(S t d)$, with a resist resonator below the active film and with a standard resonator, respectively). Geometrical parameters for all devices are listed on Table 1. Sketches of the different device architectures are shown in Figure 1a.

differences are very small. Note that for active materials which are sensitive to oxygen and moisture, one might expect that the presence of a top-layer resonator would improve the device lifetime because it would provide encapsulation. But the type of active films used in this work, e.g., dyes dispersed in passive polymers, are very photostable under operation in air without

Table 1. Geometrical and operational parameters of DFB lasers based on resonator types shown in Figure 1 and laser dyes shown in Figure 2. Dye concentration in polystyrene matrix is $1 \mathrm{wt} \%$ (for PDI-O) and $2 \mathrm{wt} \%$ (for COPVs).

\begin{tabular}{|c|c|c|c|c|c|c|c|c|c|}
\hline Device label & Dye & Resonator type & $\begin{array}{c}\alpha\left(\lambda_{\text {pump }}\right)^{a)} \\
{\left[\mathrm{cm}^{-1}\right]}\end{array}$ & $\begin{array}{c}\Lambda^{\mathrm{b})} \\
{[\mathrm{nm}]}\end{array}$ & $\begin{array}{c}d^{c)} \\
{[\mathrm{nm}]}\end{array}$ & $\begin{array}{c}\mathrm{t}^{\mathrm{d})} \\
{[\mathrm{nm}]}\end{array}$ & $\begin{array}{c}h^{\mathrm{e})} \\
{[\mathrm{nm}]}\end{array}$ & $\begin{array}{l}\lambda_{\text {DFB }}{ }^{f]} \\
{[n m]}\end{array}$ & $\begin{array}{c}I_{\text {th-DFB }}{ }^{\mathrm{g})} \\
{\left[\mathrm{kW} \mathrm{cm} \mathrm{cm}^{-2}\right]}\end{array}$ \\
\hline $\mathrm{O}\left(\mathrm{R}_{\mathrm{T}}\right)$ & PDI-O & $\mathrm{R}_{\mathrm{T}}$ & $2.4 \times 10^{3}$ & 373 & 90 & 0 & 605 & 582.8 & 2.5 \\
\hline $\mathrm{O}\left(\mathrm{R}_{\mathrm{T}}{ }^{\prime \prime}\right)$ & PDI-O & $\mathrm{R}_{\mathrm{T}}$ & $2.4 \times 10^{3}$ & 373 & 60 & 60 & 597 & 583.5 & 2.7 \\
\hline$O\left(R_{T}{ }^{\prime \prime \prime}\right)$ & PDI-O & $\mathrm{R}_{\mathrm{T}}$ & $2.4 \times 10^{3}$ & 377 & 60 & 60 & 310 & 575.9 & 7.0 \\
\hline$O(S t d)$ & PDI-O & Std & $2.4 \times 10^{3}$ & 376 & 60 & - & 600 & 584.4 & 2.3 \\
\hline$O\left(R_{B}{ }^{\prime \prime}\right)$ & PDI-O & $\mathrm{R}_{\mathrm{B}}$ & $2.4 \times 10^{3}$ & 373 & 50 & 80 & 601 & 582.6 & 18 \\
\hline$O\left(R_{B}{ }^{I I I}\right)$ & PDI-O & $\mathrm{R}_{\mathrm{B}}$ & $2.4 \times 10^{3}$ & 377 & 50 & 80 & 315 & 575.3 & 130 \\
\hline $3\left(R_{T}\right)$ & COPV3 & $\mathrm{R}_{\mathrm{T}}$ & $1.9 \times 10^{3}$ & 326 & 70 & 40 & 551 & 521.4 & 1.7 \\
\hline $4\left(R_{T}\right)$ & COPV4 & $\mathrm{R}_{\mathrm{T}}$ & $1.1 \times 10^{3}$ & 351 & 80 & 20 & 630 & 552.3 & 4.1 \\
\hline $6\left(R_{T}\right)$ & COPV6 & $\mathrm{R}_{\mathrm{T}}$ & $1.6 \times 10^{3}$ & 370 & 65 & 50 & 566 & 581.3 & 1.0 \\
\hline
\end{tabular}

a) Absorption coefficient at the pump wavelength, $532 \mathrm{~nm}$ for PDIO and COPV6 devices and $436 \mathrm{~nm}$ for COPV3 and COPV4 devices (error $\approx 5 \%$ ). b) Grating period (error is

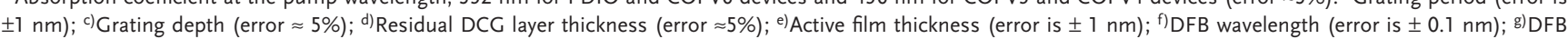
threshold, determined from output intensity versus incident pump intensity curves, such as the one shown in Figure $4 \mathrm{c}$. Error $\approx 10 \%$, estimated statistically as the s.d. from measurements on several nominally identical samples. 
the need of encapsulation. Therefore, such expectation might not be applicable here, which is in fact what the experiments indicate.

\subsection{Laser Slope Efficiency, Emission Wavelength, and Beam Divergence}

One parameter that benefits from the grating being located on top of the active film is the LSE, which is determined by the plot of the total output energy as a function of the pump energy (see the Experimental Section for details). Indeed, $\mathrm{R}_{\mathrm{T}}$-type $\mathrm{DFB}$ lasers such as $\mathrm{O}\left(\mathrm{R}_{\mathrm{T}}\right)$ and $\mathrm{O}\left(\mathrm{R}_{\mathrm{T}}{ }^{\mathrm{II}}\right)$ exhibit LSE values that are by factors of 3 and 20 higher than those of Std- $[\mathrm{O}(\mathrm{Std})$ to be compared to $\left.\mathrm{O}\left(\mathrm{R}_{\mathrm{T}}\right)\right]$ and $\mathrm{R}_{\mathrm{B}}$-type lasers $\left[\mathrm{O}\left(\mathrm{R}_{\mathrm{B}}{ }^{\mathrm{II}}\right)\right.$ to be compared to $\mathrm{O}\left(\mathrm{R}_{\mathrm{T}}^{\mathrm{II}}\right)$ ], respectively (Figure $4 \mathrm{~d}$ and Table 2 ). As expected, $6\left(\mathrm{R}_{\mathrm{T}}\right)$ and $3\left(R_{T}\right)$ lasers afford LSE values of 1.5 and 1.4 , respectively, which are similar to those of the $O\left(R_{T}\right)$ device (LSE $\left.=1.4\right)$, given their identical resonator configuration and similar thresholds. The higher efficiency of the $\mathrm{R}_{\mathrm{T}}$ type configuration was attributed to a better diffraction efficiency $(\eta)$ of the grating to extract light from the waveguide. To support this hypothesis, we calculated the parameter $\gamma=\pi \Delta n d / \lambda$ for various PDI-O-based devices (Table 2), wherein $\Delta n$ refers to the index modulation, i.e., the difference between the refractive indexes of the two media separating the grating interface, $d$ to the groove depth, and $\lambda$ to the wavelength of the diffracted light (in this case: $\left.\lambda_{\mathrm{DFB}}\right)$. The parameter $\gamma$ represents half of the maximum phase difference between rays perpendicular to the grating plane and is commonly used in the context of diffracting gratings to characterize their $\eta$ performance. ${ }^{[46]}$ For the type of gratings used in this work, i.e., thin-relief sinusoidal gratings, the condition $\gamma<<\pi$ applies, and $\eta$ increases with $\gamma$, according to: $\eta(i$ order $)=$ $J_{i}^{2}(2 \gamma)$, where $J_{i}$ is the $i$-order Bessel function. The data shown in Table 2 revealed a correlation between LSE and $\gamma$, i.e., for a given grating, the LSE value increases with $\gamma$. This correlation is quantitatively satisfactory with an error below $20 \%$ for lasers with holographic resonators (the LSE and $\gamma$ values for the $\mathrm{R}_{\mathrm{T}}$-type lasers are both $\approx 22$ times larger than the LSE and $\gamma$ values for the $\mathrm{R}_{\mathrm{B}}$-type laser). The correlation is not that precise when compared to the Std configuration (the LSE for the $\mathrm{R}_{\mathrm{T}}$-type lasers is approximately threefold higher than that for the Std laser, while the $\gamma$ parameter differs by a factor of $\approx 5$ ),

Table 2. Additional experimental and theoretical parameters for a selection of PDI-O based DFB lasers.

\begin{tabular}{|c|c|c|c|c|c|c|}
\hline Device label & Resonator type & $\begin{array}{c}\text { LSEa) }^{\text {a }} \\
\end{array}$ & $\gamma^{b)}$ & $\begin{array}{c}\lambda_{\mathrm{DFB}}{ }^{\mathrm{c})} \\
{[\mathrm{nm}]}\end{array}$ & $n_{\mathrm{eff}}^{\mathrm{d})}$ & $\begin{array}{c}\lambda_{\text {Bragg }}{ }^{\mathrm{e})} \\
{[\mathrm{nm}]}\end{array}$ \\
\hline $\mathrm{O}\left(\mathrm{R}_{\mathrm{T}}\right)$ & $\mathrm{R}_{\mathrm{T}}$ & 1.4 & 0.26 & 582.8 & 1.558 & 581.0 \\
\hline$O\left(R_{T}^{\prime \prime}\right)$ & $\mathrm{R}_{\mathrm{T}}$ & 1.3 & 0.18 & 583.5 & 1.561 & 582.1 \\
\hline $\mathrm{O}(\mathrm{Std})$ & Std & 0.42 & 0.044 & 584.4 & 1.555 & 584.7 \\
\hline $\mathrm{O}\left(\mathrm{R}_{\mathrm{B}}{ }^{\prime \prime}\right)$ & $R_{B}$ & 0.061 & 0.012 & 582.6 & 1.560 & 582.0 \\
\hline
\end{tabular}

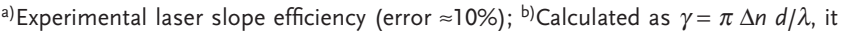
is a parameter related to $i$-order grating diffraction efficiency, $\eta(i)$, according to $\eta(i)=J_{i}{ }^{2}(2 \gamma)$, where $J_{i}$ is the $i$-order Bessel function; ${ }^{c}$ ) DFB wavelength (error is $\pm 0.1 \mathrm{~nm}) ;{ }^{d)}$ Calculated effective index for the guiding layer for each device struc-

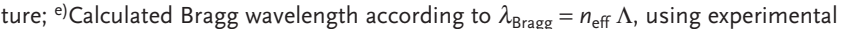
$\Lambda$ and calculated $n_{\text {eff }}$ values. which might be a consequence of the different grating profile (sinusoidal for the $\mathrm{R}_{\mathrm{T}}$-type and square for the Std-types) ${ }^{[47]}$ or of the different grating quality. The correlation of higher LSE with higher grating efficiency is in agreement with a previous work about Std-type devices with different modulation depths. ${ }^{[48]}$ They found an increase of the slope laser efficiency with increasing depth, which was explained by an increased output coupling due to higher overlap of the grating and the guided light mode. With regards to the thresholds, one would expect (for comparable devices) to see a higher threshold as a consequence of the higher LSE, because the increase of the outcoupling losses would lead to a decrease in the net gain and therefore to an increase of the threshold. But this expectation is not complied when comparing results for $R_{T}$ and $R_{B}$ devices [see data in Tables 1 and 2 for devices $O\left(R_{T}{ }^{I I}\right)$ and $O\left(R_{B}{ }^{I I}\right)$ ]. But, it should be remarked that the two architectures $R_{T}$ and $R_{B}$ cannot be easily compared for this purpose: in the former, the active film thickness is uniform across the device, while in the $\mathrm{R}_{\mathrm{B}}$-type device, it is modulated; and this feature is expected to have an effect on the threshold. Actually, for a proper analysis of this issue, one should consider devices with the same type of architecture and study the effect on the LSE and the threshold of varying a given geometrical device parameter which allows changing the amount of outcoupled light, while preserving the same waveguide properties. In such a system, the correlation of higher LSE and higher threshold would most likely hold. For that purpose, we prepared some additional PDI-O $\mathrm{R}_{\mathrm{T}}$-type devices (data not shown in the Tables), all with $h \approx 570 \mathrm{~nm}$, no residual layer $(t=0)$ and different gratings depths, $d(90,125$ and $185 \mathrm{~nm})$. The devices showed similar LSE values $(1.3 \%)$, despite their different $d$, indicating that the range of modulation depths explored is too small to see differences. Their thresholds were also similar (around $2 \mathrm{~kW} \mathrm{~cm}^{-2}$ ). Further experiments exploring a larger range of modulation depths are currently being performed which will hopefully lead to a clear understanding of this issue. Interestingly, in the Std-type devices prepared by Döring et al, ${ }^{[48]}$ which showed an increase of the laser slope efficiency with increasing corrugation depth, no differences in the thresholds were found. This was attributed to a certain loss channel associated to imperfections of the gratings, so internal losses were larger and therefore dominant over the outcoupling losses. Finally, with regards to the $\mathrm{R}_{\mathrm{B}}$-type devices prepared in the present work, whose LSE values are much smaller than those of the $R_{B}$-type ones, their thresholds are higher; but this is because their waveguide propagation losses are larger as already discussed in Section 2.2.

Table 2 also includes calculated $n_{\text {eff }}$ and $\lambda_{\text {Bragg }}$ values. A comparison of the calculated $\lambda_{\text {Bragg }}$ values, which correspond to the forbidden band, to the experimental $\lambda_{\mathrm{DFB}}$ values may afford a better understanding of the underlying physical mechanisms (index coupling and/or gain coupling) involved in the laser emission process. In agreement with previous studies on PDIO-based Std devices, ${ }^{[38]}$ the laser emission $\left(\lambda_{\mathrm{DFB}}\right)$ is slightly redshifted with respect to $\lambda_{\text {Bragg }}$. Data shown in Table 2 show that the separation between $\lambda_{\mathrm{DFB}}$ and $\lambda_{\mathrm{Bragg}}$ is slightly larger for the $\mathrm{R}_{\mathrm{T}}$-type lasers (1.4-1.8 $\mathrm{nm}$ ) than for $\mathrm{R}_{\mathrm{B}}$-type and Std $(<1 \mathrm{~nm})$ lasers. This can be rationalized by the fact that only index coupling contributes to the laser emission in $\mathrm{R}_{\mathrm{T}}$-type devices, given the uniform thickness of the active film. On the other hand, 
in both $\mathrm{R}_{\mathrm{B}}$-type and Std devices, index and gain coupling contribute to the laser emission. ${ }^{[38]}$

For all DFB architectures in this work $\left(R_{T}, R_{B}\right.$, and Std), similar beam divergence values were observed in directions perpendicular $\left(5 \times 10^{-3} \mathrm{rad}\right)$ and parallel $(0.2 \mathrm{rad})$ to the grating lines.

\subsection{Color Tunability in a Single Device}

A very important characteristic of the $\mathrm{R}_{\mathrm{T}}$-type devices proposed herein is the possibility to tune their laser emission wavelength $\left(\lambda_{\mathrm{DFB}}\right)$ in a single device, while keeping the threshold value low due to the constant thickness of the active film across the whole device. This can be achieved by engraving gratings of different period in different sections of the top resist layer (Figure 5a), which can be easily accomplished by means of HL. Device operation is then achieved by focusing the pump beam on different sections of the device.

An $\mathrm{R}_{\mathrm{T}}$-type device with a PDI-O/PS active film of uniform thickness $(h=560 \mathrm{~nm}$ ) and six gratings of different period (in the range $\Lambda=356-383 \mathrm{~nm}$ ), all with $d=90 \mathrm{~nm}$ and no residual layer $(t=0)$, engraved on different regions of the top DCG layer, afforded a broad tunability range of $\approx 50 \mathrm{~nm}$ (emission: 550-600 nm) (Figure 5b).

Importantly, the threshold of the device remained below $5 \mathrm{~kW} \mathrm{~cm}{ }^{-2}$ for most of the emission wavelength range (Figure $5 \mathrm{c}$ ). The lowest threshold was obtained for $\lambda_{\mathrm{DFB}} \approx \lambda_{\mathrm{ASE}}=579 \mathrm{~nm}$, i.e., for the wavelength with maximum gain. The device with $\Lambda=356 \mathrm{~nm}\left(\lambda_{\mathrm{DFB}}=558 \mathrm{~nm}\right)$ also showed a reasonably low threshold $\left(16 \mathrm{~kW} \mathrm{~cm}{ }^{-2}\right)$, which was slightly increased due to selfabsorption. It should be noted that the tunability range reported here $(50 \mathrm{~nm})$ can be expanded even further, although at the expense of the laser threshold. With the emission wavelength deviating from $\lambda_{\mathrm{ASE}}=579 \mathrm{~nm}$, the gain decreases. Moreover, lasers that emit at lower wavelengths, face limitations that arise from self-absorption. Despite these restrictions, a remarkable aspect of the approach proposed here is the constant thickness of the active film across the device, which ensures a fixed number of waveguide modes, a good waveguide mode confinement, as well as a constant film absorption and photoluminescence (PL) efficiency. All of these parameters are crucial for a successful and reproducible performance.

\section{Conclusions}

The $\mathrm{R}_{\mathrm{T}}$-type device proposed herein represents the first example for a laser that contains a resonator and an active film consisting of solution-processable organic materials and shows an outstanding performance in terms of threshold, operational durability, laser slope efficiency, and multi-wavelength emission in a single device. Crucial for the successful performance are the selection of the device architecture and the use of very efficient and photostable active materials. The device architecture is based on a top-layer resonator, i.e., a DCG photoresist layer with engraved 1D relief gratings, deposited on top of an active film composed of PS doped with either PDI-O or a COPV derivative. Most remarkably, the deposition of the DCG layer in solution does not affect the active film, which should be attributed to the (a)
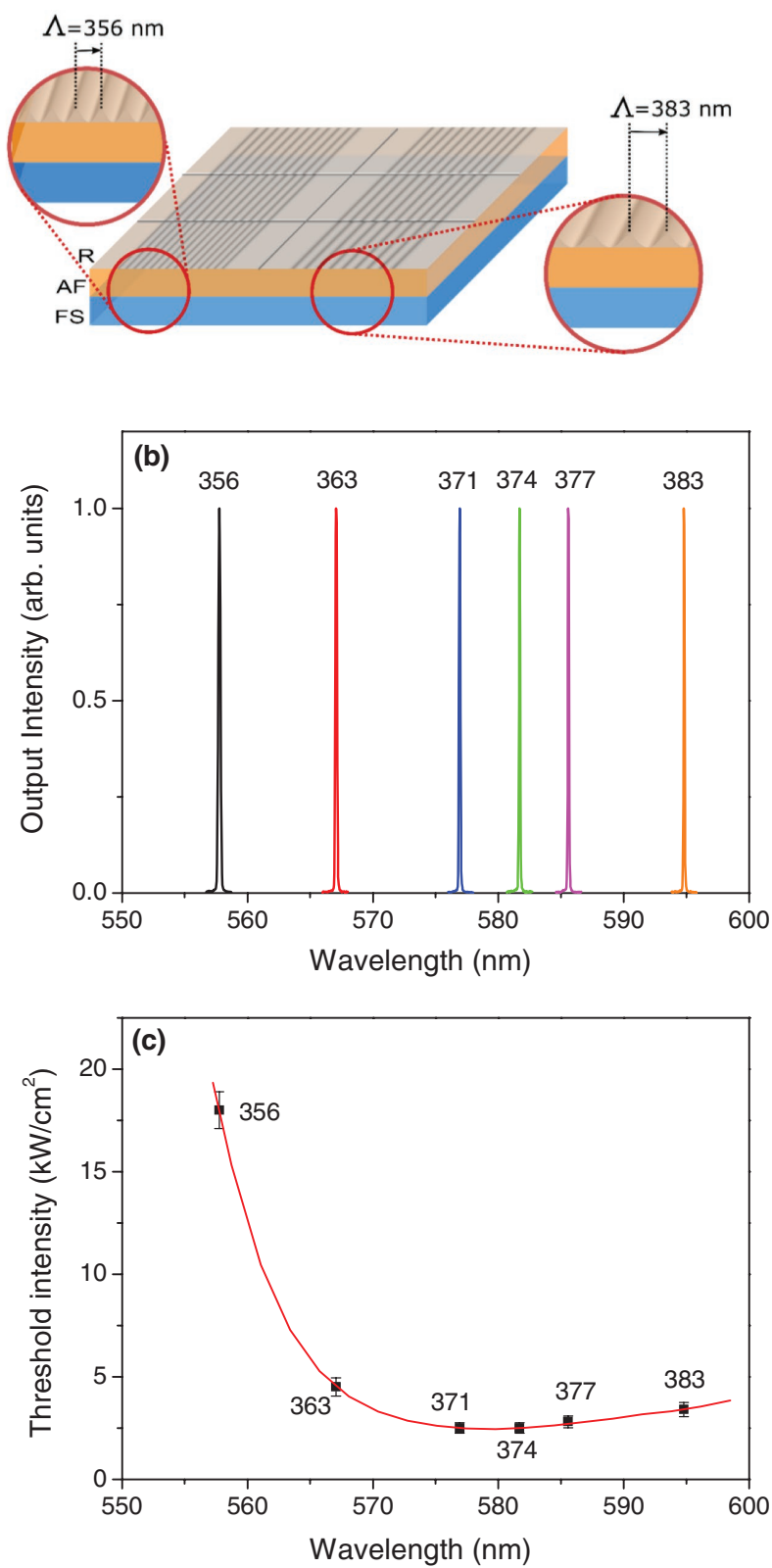

Figure 5. Color tunability in a single device. a) Sketch of the structure of an $\mathrm{R}_{\mathrm{T}}$-type DFB laser based on a $560 \mathrm{~nm}$ thick PDI-O-doped PS film with six different gratings, with periods $(\Lambda)$ of $356,363,371,374,377$, and $383 \mathrm{~nm}$, all with depth $d=90 \mathrm{~nm}$ and no residual layer, $t=0$. b) DFB spectra and c) DFB threshold, obtained from the different sections of the device, versus the corresponding emission wavelength. For each curve or data point in the figures, the corresponding $\Lambda$ value (in $\mathrm{nm}$ ) is indicated next to it.

immiscibility of the PS matrix (soluble in organic solvents) and the DCG film (soluble in water). This feature can be extended to other active materials, which are not necessarily restricted to organic compounds, as the only requirement is the insolubility in water. In this context, it should be worth pointing out that most organic active materials used in organic lasers are soluble in organic solvents, but not in water. Another important feature is that the relief grating, once the DCG film has been holographically exposed, is accomplished by a dry development 
under an oxygen plasma stream. This stands in contrast to the wet process traditionally used in conventional holography to generate volume patterns. These fabrication aspects are relevant for the successful operation of devices including resist resonators.

The lasers prepared in this study emit in the 520-595 nm range, which can be easily extended to other spectral regions by selecting other laser dyes and appropriate grating periods. Their performance is excellent, considering that the resonator is polymeric. In particular, they show narrow linewidths $(<0.13 \mathrm{~nm})$, low thresholds $\left(\approx 1 \mathrm{~kW} \mathrm{~cm}{ }^{-2}\right)$, and long operational lifetimes $\left(7 \times 10^{5}\right.$ pump pulses $)$, similar to those of Std-type lasers. An aspect of particular importance is that the LSE of the proposed devices is approximately threefold higher than that of Std-type lasers. This is due to the location of the resonator on top of the active film. Moreover, the improved performance of the proposed top-layer resonator devices is even more significant when compared to other devices that contain the organic resonators below the active film; the latter exhibit 20-fold lower LSE and sevenfold higher threshold values.

Finally, the use of a top-layer resonator configuration, combined with the large device size $(\approx \mathrm{cm})$, facilitates the fabrication of various gratings in a given device, i.e., the laser can emit at various wavelengths within a broad range $(\approx 50 \mathrm{~nm})$, while the threshold is maintained at a low level $\left(<5 \mathrm{~kW} \mathrm{~cm}^{-2}\right)$ due to the constant thickness of the active film across the device.

Overall, this work paves the way towards the fabrication of all-organic thin-film lasers, which can satisfy all the requirements for the development of applications: low cost, mechanical flexibility, low threshold, long operational durability, high efficiency, and wavelength tunability. Further developments will focus on the development of all-organic devices, e.g., by the use of a polymeric substrate ${ }^{[21]}$ instead of FS; or of continuously tunable devices, for example by including photochromic molecules in the active film, ${ }^{[29]}$ or by adding an additional layer with a NLO chromophore. ${ }^{[31]}$ The use of other photoresists, particularly with elastic properties, would also be interesting for the prospect of an electrically tunable laser. ${ }^{[30]}$ Finally, also prospectful will be the use of other high-performing active materials, such as neat films of organic semiconductors, in which case (or others in which the active material is sensitive to oxygen and moisture), the use of the $\mathrm{R}_{\mathrm{T}}$ configuration might indirectly provide an additional function as a cladding protective layer to avoid photodegradation. From a broader perspective, this grating configuration and resist material could also be used for other nonorganic active laser materials ${ }^{[49]}$ that are insoluble in water; or for other optoelectronic devices, such as light emitting diodes ${ }^{[50]}$ or solar cells, ${ }^{[51]}$ with the purpose of improving their efficiency to extract or collect light.

\section{Experimental Section}

DFB Resonator and Thin Film Fabrication: Fabrication of $\mathrm{R}_{\mathrm{T}^{-} \text {-type lasers }}$ consisted of the following steps: (1) Active layer deposition: a PS film containing either PDI-O (1 wt\%) or a COPV compound (2 wt\%) was spin coated over a FS substrate from a toluene solution; (2) Photoresist deposition: a DCG layer was spin coated over the active layer prepared in step 1 , from a hot water solution $\left(40^{\circ} \mathrm{C}\right)$ containing $\approx 4 \%$ of DCG; (3) Grating recording: a ID grating, with $\Lambda$ in the range $326-383 \mathrm{~nm}$, was recorded by $\mathrm{HL}$, with light from an Argon laser emitting at $488 \mathrm{~nm}$ in a simple and stable setup, in which a mirror is attached with a $90^{\circ}$ angle to the sample holder (a scheme of the setup can be found elsewhere). ${ }^{[52]}$ The light intensity pattern between exposed and unexposed areas is translated in hardness variations in DCG. After desensitizing in a cool water bath $\left(15^{\circ} \mathrm{C}\right)$, a relief grating is obtained by dry development in an oxygen plasma. ${ }^{[53,54]}$

Resonator fabrication for $\mathrm{R}_{\mathrm{B}}$-type lasers was done following the same method as for the $R_{T}$ ones, but in this case the DCC layer was deposited over a FS substrate and once the relief grating was engraved on the resist, the organic active film was deposited on top of it. ${ }^{[20,44]}$

Gratings for Std-type lasers were prepared by thermal-NIL over a thermoplastic resist and transferred, by means of reactive ion etching, to FS substrates, as previously described. ${ }^{[9]}$

Morphological and Optical Characterization: Experimental device parameters were determined as follows: the refractive index and thickness of the active film and initial DCG layer, from the interference pattern of their transmission film spectra, ${ }^{[55,56]}$ obtained in a Jasco V-650 spectrophotometer; the grating period, by comparing diffraction patterns to those of calibrated reference gratings; the grating depth and thickness of the residual layers, from the initial thickness of the DCC layer and the selectivity of the development process. The selectivity, defined as the ratio of the development rate of nonexposed to the exposed areas, increases with the average exposure, reaching a value of about 2 for an exposure of $400 \mathrm{~mJ} \mathrm{~cm}{ }^{-2}$. Grating depths were confirmed by AFM with an NT-MDT apparatus, model NTEGRA PRIMA.

Laser characterization was performed under excitation with a frequency-doubled Neodimium Yttrium Aluminium Garnet, Nd:YAG, laser $(10 \mathrm{~ns}, 10 \mathrm{~Hz})$ emitting at $532 \mathrm{~nm}$, for devices based on PDI-O and COPV6, and at the $436 \mathrm{~nm}$ light provided by a Raman cell pumped with the $532 \mathrm{~nm}$ line of the Nd:YAG laser, for those based on COPV3 and COPV4. The pump beam over the sample was elliptical, with a minor axis of $1.1 \mathrm{~mm}$, and incident at $a \approx 20^{\circ}$ angle with respect to the perpendicular to the film plane. The emitted light was collected in reflectance, perpendicularly to the surface with an Ocean Optics USB2000 fiber spectrometer (resolution $1.3 \mathrm{~nm}$ ) placed at about $1 \mathrm{~cm}$ from the sample. For spectral shape inspection a MAYA spectrometer was used $(0.13 \mathrm{~nm}$ resolution). The energy of the pulses was varied using neutral density filters and the laser threshold was determined as the lowest energy at which laser emission occurs. The photostability was studied by recording the DFB intensity as a function of time and quantified by means of the half-life parameter. LSE measurements were performed in a setup slightly modified for increasing the accuracy: A $45^{\circ}$ dichroic mirror was used to direct the pump beam perpendicularly to the sample, and to block any of the pump light, before collecting the laser emission (from the side of the film which is pumped) with high sensitivity energy detectors Ophir PD10-C and PD10-p)-C (resolutions of 1 and $0.01 \mathrm{~nJ}$, respectively). LSE values were obtained by a linear fit of the output energy versus the pump energy curves. The beam divergence was determined from direct measurements of the far-field pattern in directions perpendicular and parallel to the resonator grating lines.

Calculations of Effective Refractive Index: Calculations of the $n_{\text {eff }}$ values, for subsequent determination (through Equation (1)) of $\lambda_{\text {Bragg, }}$ were performed by means of a free-access software program (1D mode solver for dielectric multilayer slab waveguides). ${ }^{[57]}$ For $R_{T}$ and $R_{B}$-type devices, the DCG resonator was simulated by two layers, one of uniform thickness $t$ and the refractive index of the DCG (see Figure 1a) and the other one, of thickness $d$, and a refractive index equal to the average index of the two media at each side of the corrugated surface (air and $D C G$, or DCG and PS, for $R_{T}$ and $R_{B}$ type, devices, respectively). The refractive index values used in the calculations (at $\lambda=580 \mathrm{~nm}$ ) were: 1.540, for exposed and developed DCG; 1.592 for dye-doped PS, which corresponds to the value of nondoped PS; and 1.459 for FS.

\section{Acknowledgements}

The Spanish team acknowledges support from the Spanish Government (MINECO) and the European Community (FEDER) through Grant Nos. MAT2011-28167-C02-01 and MAT2015-66586-R. M.M.-V. was partly supported by a MINECO FPI fellowship (No. BES-2009-020747) and 
by a Junta de Castilla y León grant (No. SA046U16). Japanese authors thank the financial support from the MEXT $(16 \mathrm{H} 04106$ for H.T. and $15 \mathrm{H} 05754$ for E.N.). Dr. Merino and Dr. Retolaza, at Tekniker (Spain), are acknowledged for supplying the NIL fabricated resonators. The authors also thank I. Garcés for technical assistance.

\section{Conflict of Interest}

The authors declare no conflict of interest.

\section{Keywords}

distributed feedback lasers, organic lasers, polymeric resonators, solution-processed

Received: March 13, 2017

Revised: May 19, 2017

Published online: August 1, 2017

[1] S. Chénais, S. Forget, Polym. Int. 2012, 61, 390.

[2] C. Grivas, M. Pollnau, Laser Photonics Rev. 2012, 6, 419

[3] C. Grivas, Prog. Quantum Electron. 2016, 3, 45.

[4] A. Kuehne, M. C. Gather, Chem. Rev. 2016, 116, 12823.

[5] C. Vannahme, S. Klinkhammer, U. Lemmer, T. Mappes, Opt. Express 2011, 19, 8179

[6] J. Clark, G. Lanzani, Nat. Photonics 2010, 4, 438.

[7] E. Heydari, J. Buller, E. Wischerchoff, A. Laschewsky, S. Döring, J. Stumpe, Adv. Opt. Mater. 2014, 2, 137.

[8] Y. Wang, P. O. Morawska, A. L. Kanibolotsky, P. J. Skabara, G. A. Turnbull, I. D. W. Samuel, Laser Photonics Rev. 2013, 7, L71.

[9] M. Morales-Vidal, P. G. Boj, J. A. Quintana, J. M. Villalvilla, A. Retolaza, S. Merino, M. A. Díaz-García, Sens. Actuators, B 2015, 220, 1368.

[10] P. G. Boj, M. Morales-Vidal, J. M. Villalvilla, J. A. Quintana, A. Marcilla, M. A. Díaz-García, Sens. Actuators, B 2016, 232, 605.

[11] D. Xia, Z. Ku, S. C. Lee, S. R. J. Brueck, Adv. Mater. 2011, 23, 147.

[12] M. Salerno, G. Gigli, M. Zavelani-Rossi, S. Perissinotto, G. Lanzani, Appl. Phys. Lett. 2007, 90, 111110.

[13] J. A. Rogers, M. Meier, A. Dodabalapur, E. J. Laskowski, M. A. Cappuzzo, Appl. Phys. Lett. 1999, 74, 3257.

[14] M. Gaal, C. Gadermaier, H. Plank, E. Moderegger, A. Pogantsch, G. Leising, E. J. W. List, Adv. Mater. 2003, 15, 1165.

[15] E. Mele, A. Camposeo, R. Stabile, P. Del Carro, F. Di Benedetto, L. Persano, R. Cingolani, D. Pisignano, Appl. Phys. Lett. 2006, 89, 131109.

[16] M. B. Christiansen, M. Schøler, A. Kristensen, Opt. Express 2007, 15, 3931.

[17] M. G. Ramírez, P. G. Boj, V. Navarro-Fuster, I. Vragovic, J. M. Villalvilla, I. Alonso, V. Trabadelo, S. Merino, M. A. Díaz-García, Opt. Express 2011, 19, 22443.

[18] C. Kallinger, M. Hilmer, A. Haugeneder, M. Perner, W. Spirkl, U. Lemmer, J. Feldmann, U. Scherf, K. Müllen, A. Combert, V. Wittwer, Adv. Mater. 1998, 10, 920.

[19] G. Tsiminis, Y. Wang, A. L. Kanibolotsky, A. R. Inigo, P. J. Skabara, I. D. W. Samuel, G. A. Turnbull, Adv. Mater. 2013, 25, 2826.

[20] M. G. Ramírez, J. M. Villalvilla, J. A. Quintana, P. G. Boj, M. A. Díaz-García, Opt. Mater. Express 2014, 4, 733.

[21] J. R. C. Smirnov, Q. Zhang, R. Wannemacher, L. Wu, S. Casado, R. Xia, I. Rodríguez, J. Cabanillas-González, Sci. Rep. 2016, 6, 34565.

[22] N. Tsutsumi, S. Nagi, K. Kinashi, W. Sakai, Sci. Rep. 2016, 6, 34741.

[23] T. Zhai, X. Zhang, Z. Pang, Opt. Express 2011, 19, 6487.

[24] W. Huang, S. Shen, D. Pu, G. Wei, Y. Ye, C. Peng, L. Che, J. Phys. D: Appl. Phys. 2015, 48, 495105.

[25] D. Schneider, T. Rabe, T. Riedl, T. Dobbertin, M. Kröger, E. Becker, H.-H. Johannes, W. Kowalsky, T. Weimann, J. Wang, P. Hinze, Appl. Phys. Lett. 2004, 85, 1886.
[26] S. Klinkhammer, X. Liu, K. Huska, Y. Shen, S. Vanderheiden, S. Valouch, C. Vannahme, S. Bräse, T. Mappes, U. Lemmer, Opt. Express 2012, 20, 6357.

[27] S. Schauer, X. Liu, M. Worgull, U. Lemmer, H. Hölscher, Opt. Mater. Express 2015, 5, 576

[28] T. Ubukata, T. Isoshima, M. Hara, Adv. Mater. 2005, 17, 1630.

[29] H. Wallikewitz, G. O. Nikiforov, H. Sirringhaus, R. H. Friend, Appl. Phys. Lett. 2012, 100, 173301.

[30] S. Döring, M. Kollosche, T. Rabe, J. Stumpe, G. Kofod, Adv. Mater. 2011, 23, 4265

[31] A. Camposeo, P. Del Carro, L. Persano, D. Pisignano, Adv. Mater. 2012, 24, OP221.

[32] V. Navarro-Fuster, E. M. Calzado, P. G. Boj, J. A. Quintana, J. M. Villalvilla, M. A. Díaz-García, V. Trabadelo, A. Juarros, A. Retolaza, S. Merino, Appl. Phys. Lett. 2010, 97, 171104.

[33] M. G. Ramírez, M. Morales-Vidal, V. Navarro-Fuster, P. G. Boj, J. A. Quintana, J. M. Villalvilla, A. Retolaza, S. Merino, M. A. Díaz-García, J. Mater. Chem. C 2013, 1, 1182.

[34] M. G. Ramírez, S. Pla, P. G. Boj, J. M. Villalvilla, J. A. Quintana, M. A. Díaz-García, F. Fernández-Lázaro, A. Sastre-Santos, Adv. Opt. Mater. 2013, 1, 933.

[35] M. Morales-Vidal, P. G. Boj, J. M. Villavilla, J. A. Quintana Q. Yan, N.-T. Lin, X. Zhu, N. Ruangsupapichat, J. Casado, H. Tsuji, E. Nakamura, M. A. Díaz-García, Nat. Commun. 2015, 6,8458 .

[36] X. Zhu, H. Tsuji, J. T. López Navarrete, J. Casado, E. Nakamura, J. Am. Chem. Soc. 2012, 134, 19254.

[37] P. M. Burrezo, N.-T. Lin, K. Nakabayashi, S. Ohkoshi, E. M. Calzado, P. G. Boj, M. A. Díaz-García, C. Franco, C. Rovira, J. Veciana, M. Moos, C. Lambert, J. T. López Navarrete, H. Tsuji, E. Nakamura, J. Cassado, Angew. Chem. Int. Ed. 2017, 56, 2898

[38] V. Navarro-Fuster, I. Vragovic, E. M. Calzado, P. G. Boj, J. A. Quintana, J. M. Villalvilla, A. Retolaza, A. Juarros, D. Otaduy, S. Merino, M. A. Díaz-García, J. Appl. Phys. 2012, 112, 043104.

[39] J. Crespo, M. Pardo, M. A. Satorre, J. A. Quintana, Appl. Opt. 1993 32, 3068.

[40] H. Kogelnik, C. V. Shank, J. Appl. Phys. 1972, 43, 2327.

[41] R. F. Kazarinov, C. H. Henry, IEEE J. Quantum Electron. 1985, $21,144$.

[42] H. Ghafouri-Shiraz, Distributed Feedback Laser Diodes and Optical Tunable Filters, John Wiley \& Sons Ltd., West Sussex, UK 2003.

[43] E. M. Calzado, J. M. Villalvilla, P. G. Boj, J. A. Quintana, V. NavarroFuster, A. Retolaza, S. Merino, M. A. Díaz-García, Appl. Phys. Lett. 2012, 101, 223303

[44] M. G. Ramírez, J. A. Quintana, J. M. Villalvilla, P. G. Boj, A. Retolaza, S. Merino, M. A. Díaz-García, J. Appl. Phys. 2013, 114, 033107.

[45] E. M. Calzado, M. G. Ramírez, P. G. Boj, M. A. Díaz-García, Appl. Opt. 2012, 51, 3287.

[46] M. J. Beesley, J. G. Castledine, Appl. Opt. 1970, 9, 2720.

[47] R. Magnusson, T. K. Gaylord, J. Opt. Soc. Am. 1978, 68, 806.

[48] S. Döring, T. Rafe, J. Stumpe, Appl. Phys. Lett. 2014, 104, 263302.

[49] B. R. Sutherland, E. H. Sargent, Nat. Photonics 2016, 10, 295.

[50] S. Noda, M. Fujita, Nat. Photonics 2009, 3, 129.

[51] S. Colodrero, A. Mihi, L. Häggman, M. Ocaña, G. Boschloo, A. Hagfeldt, H. Míguez, Adv. Mater. 2009, 21, 764.

[52] E. M. Calzado, J. M. Villalvilla, P. G. Boj, J. A. Quintana, P. A. Postigo, M. A. Díaz-García, Appl. Opt. 2010, 49, 463.

[53] J. M. Villalvilla, J. Crespo, J. A. Quintana, C. Santos, J. A. Valles-Abarca, Thin Solid Films 1998, 317, 340.

[54] J. A. Quintana, P. G. Boj, J. Crespo, J. A. Vallés-Abarca, J. M. Villalvilla, Thin Solid Films 1998, 317, 343.

[55] R. Swanepoel, J. Phys. E: Sci. Instrum. 1983, 16, 1214.

[56] R. Swanepoel, J. Opt. Soc. Am. A 1985, 2, 1339.

[57] M. Hammer, 1D mode solver for dielectric multilayer slab waveguides, Software on line from Silo.Eu, http://www.computationalphotonics.eu/oms.html (accessed: February, 2017). 